\title{
Kecerdasan Majemuk Berdasarkan Neurosains
}

\section{Multiple Intelligences Based on Neuroscience}

\author{
Adib Rifqi Setiawan \\ $\Lambda$ lobatnio Research Society $(\Lambda \mathrm{RS})$ \\ Jl. Kudus - Colo, Pandak, 001/003, Colo, Kudus, 59353, Indonesia \\ adibrifqisetiawan@gmail.com \\ Surotul Ilmiyah \\ Xiangya School of Public Health, Central South University (CSU) \\ 932 Lushan S Rd, Yuelu District, Changsha, Hunan, China \\ surotul.ilmiyah@csu.edu.cn
}

\begin{abstract}
Sari
Esai ini menjelaskan teori kecerdasan majemuk yang didasarkan secara eksklusif kepada kajian empiris dalam neurosains.

Kata-kata Kunci: neurosains; pendidikan; kecerdasan majemuk;

\section{Abstract}

This essay explains the theory of multiple intelligences that is based exclusively on empirical study in neuroscience.
\end{abstract}

Keywords: education; multiple intelligences; neuroscience

\section{Pengantar}

Burhān al-Dīn al-Zarnūjī dalam buku Ta'tìm al-Muta'allim Torīq al-Ta'allum menuturkan bahwa terdapat 6 faktor penentu hasil belajar: kecerdasan, motivasi, kesabaran ketika menghadapi kesulitan, ketekunan terlibat aktif dalam pembelajaran, bimbingan guru, dan waktu belajar yang intensif (Siayah, dkk., 2020; al-Zarnūjī, 2015). Dari keenam faktor tersebut, kecerdasan menjadi faktor yang disebut lebih dulu. Tidak jarang dalam uraian teks klasik Bahasa Arab, urutan menunjukkan keutamaan. Apakah urutan 6 faktor penentu hasil belajar tersebut berarti lebih mengutamakan kecerdasan daripada motivasi, bukanlah persoalan berarti. Yang jelas, kecerdasan memiliki peran penting terhadap hasil belajar. Tuturan al-Zarnūjī (2015) didukung antara lain oleh Jung \& Haier (2007) yang mengungkap bahwa tidak ada konsep yang lebih penting dalam pendidikan daripada konsep kecerdasan.

Konsep kecerdasan dalam sejarah telah mengalami banyak perubahan dalam benak para ilmuwan dan pakar pendidikan. Banyak yang telah meninggalkan konsep ini sebagian atau seluruhnya. Sebagai gantinya mereka menyelidiki kemampuan kognitif, pemecahan masalah, maupun kecakapan memproses informasi. Namun, banyak juga yang terus mendukung konsep kecerdasan dengan cara beragam. Misalnya dengan cara menyelidiki sistem saraf fungsional yang mendasari pencapaian intelektual. Salah satu konsep terkait kecerdasan yang adalah kecerdasan majemuk (multiple intelligences). 
Kecerdasan majemuk (multiple intelligences) yang dipekenalkan oleh Howard Earl Gardner melalui buku Frame of Mind: Theory of Multiple Intelligences merupakan gagasan revolusioner pada 1983 (Gardner, 2011; Candler, 2011). Sebelumnya psikolog tertarik kepada kecerdasan umum (general intelligence), yakni kemampuan seseorang untuk memecahkan masalah dan menerapkan penalaran logis di berbagai disiplin ilmu. Gagasan kecerdasan umum sebagian dipopulerkan oleh tes IQ (intelligence quotient) pada awal 1900an untuk menilai kemampuan anak dalam memahami, bernalar, dan membuat penilaian (Shearer \& Karanian, 2017; University of Minnesota, 2010).

Tes IQ membantu menjelaskan alasan tentang keunggulan beberapa pelajar dalam banyak mata pelajaran. Namun, Gardner (2011) menganggap konsep itu terlalu terbatas. Kegemaran bermain piano memunculkan pertanyaan tentang alasan seni tidak dimasukkan dalam diskusi tentang kecerdasan. Sebagai pelajar pascasarjana yang mempelajari psikologi pada 1960-an, Howard Earl Gardner merasa "tersentak oleh ketiadaan virtual seni dalam buku teks utama." (Gardner, 2011).

Pertanyaan dan sentakan itu menanamkan benih yang tumbuh ke dalam wawasan besar Howard Earl Gardner, yakni anggapan umum tentang kecerdasan tunggal tidak sesuai dengan dunia yang dia amati. Wolfgang Amadeus Mozart, pianits paling digandurngi Howard Gardner, diambil sebagai contoh untuk bahwa kejeniusan dalam menggubah nada hanya dapat dijelaskan oleh kecerdasan musik (Gardner, 2011). Dari sinilah Howard Earl Gardner mulai mempertanyakan, "Bukankah masalahnya bahwa semua orang menunjukkan berbagai kemampuan intelektual-dari bahasa hingga sosial ke logika-yang sering kali saling menguatkan, serta berubah seiring waktu berdasarkan minat dan upaya seseorang yang berubah?" (Gardner, 2011).

Beberapa hipotesis untuk pertanyaan tersebut mulai dikonfirmasi oleh penelitian dari neurosains (neuroscience, ilmu saraf). Misalnya ulasan Fuchs dan Flügge (2014) menyampaikan beberapa bukti yang secara dramatis mengubah pemahaman kita tentang perkembangan otak. Penyampaian tersebut mengungkapkan bahwa kecerdasan manusia terus tumbuh dan berubah menjadi matang (Fuchs dan Flügge, 2014). Kweldju (2015) juga menyampaikan pembahasan serupa yang fokus terhadap cara kerja otak ketika membaca. Uraian yang disampaikan mengesampingkan gagasan bahwa membaca terjadi di area otak yang berbeda, sebaliknya ditemukan bahwa pemrosesan bahasa melibatkan semua fungsi kognitif manusia, yang berarti tidak hanya pemrosesan visual tetapi juga beberapa hal lain, seperti perhatian, penalaran abstrak, dan kerja memori (Kweldju, 2015).

Lalu, sebagai pelaku pendidikan di lapangan, bagaimana pendidik sebaiknya menanggapi gagasan kecerdasan majemuk? Khoirul Umam, pendidik asal Pondok Pesantren Ath-Thullab, Madrasah Tasywiquth Thullab Salafiyyah (TBS), ketika ngopi serta Syarofis Siayah, dokter asal Universitas Islam Malang (UNISMA) dalam obrolan luring pada saat bersamaan pada 26 Juni 2019 lalu menyampaikan bahwa gagasan kecerdasan majemuk perlu ditanggapi positif agar keefektifan pembelajaran bisa maksimal dan hasil belajar dapat optimal. Howard Earl Gardner (2011) sendiri berpendapat selaras terhadap keduanya sembari memperingatkan agar kecerdasan majemuk tidak boleh dijadikan tujuan pendidikan."Tujuan pendidikan perlu mencerminkan nilai seseorang (individu atau masyarakat) sendiri, dan nilai-nilai ini tidak pernah bisa datang secara sederhana atau langsung dari teori ilmiah." (Gardner, 2011).

Dampak paling kentara dari ketiga tuturan tersebut terhadap kami ialah perubahan urutan faktor terkait profil hasil belajar serta pertimbangan kecerdasan majemuk dalam penelitian. 
Mulanya kami meletakkan kecerdasan setelah motivasi, atas dasar pengalaman pribadi selama belajar. Selain itu, ketika mempertimbangkan beberapa faktor terkait hasil belajar, belum sempat terpikir untuk memasukkan kecerdasan majemuk sebagai bagian dari faktor tersebut.

Berdasarkan informasi yang disampaikan, esai ini mengurai kajian pustaka terkait riset neurosains terhadap kecerdasan majemuk. Meski telah terdapat banyak pembahasan tentang neurosains terkait pendidikan, tampak hanya memberi sedikit hasil sehubungan dengan praktik mengajar (Clement Lovat, 2012; Oliver, 2011). Kami berpendapat bahwa perkembangan neurosains tentang peristiwa yang terjadi di otak ketika manusia belajar dapat memberi manfaat kepada pendidik, terutama sebagai bahan dalam mempertimbangkan penggunaan model pembelajaran tertentu. Pengertian terhadap neurosains terkait pendidikan dapat mengarah kepada hasil yang optimal untuk setiap praktik pembelajaran.

\section{PEMBAHASAN}

Kilasan singkat linikala kemunculan gagasan kecerdasan majemuk serta obrolan spontan yang dialami memberi dasar kepada kami untuk berada dalam posisi menanggai gagasan kecerdasan majemuk secara positif. Kami melihat bahwa terdapat 2 dampak langsung terhadap pembelajaran ketika gagasan kecerdasan majemuk diterapkan secara operasional. Pertama, pelajar perlu diberi banyak cara untuk mengakses informasi. Pemberian ini bukan bertujuan untuk membuat pembelajaran lebih menarik, melainkan sebagai sarana melatih pelajar agar cenderung mengerti informasi yang disajikan dengan cara yang berbeda. Dalam praktik pelaksanaan dan penilaian pembelajaran, hal ini kerap kami wujudkan dalam bentuk meminta menyajikan informasi melalui beragam representasi, seperti ilustrasi, tabel, dan diagram. Kedua, pembelajaran sebaiknya dilakukan secara individual. Cara ini dipandang lebih sesuai dengan kebutuhan dan minat pelajar, bahkan walau sekelompok pelajar punya gaya belajar yang seragam. Sayang dalam praktiknya, kami baru bisa melakukan pembelajaran individual ketika memandu Musyāfahah al-Qur'ān dan Sorogan Kitab Kuning.

Walau terasa logis, gagasan kecerdasan majemuk kerap mendapat serangan karena dianggap tidak memiliki bukti empiris. Lynn Waterhouse misalnya, berpendapat bahwa karena kecerdasan majemuk memiliki dukungan empiris yang tidak memadai dan tidak konsisten dengan temuan neurosains kognitif, teori ini tidak boleh diterapkan dalam pendidikan (Waterhouse, 2006). Gardner \& Moran (2006) menanggapi pendapat tersebut dengan menganggap bahwa ulasan yang disampaikan justru salah paham dan terlalu menyederhanakan teori kecerdasan majemuk serta klaim yang disampaikan tidak selarasa dengan data yang disajikan. Singkatnya, gagasan tentang kecerdasan majemuk masih kontroversial. Walau belum diterima sebagai teori ilmiah yang dikembangkan sepenuhnya, boleh dikatakan bahwa daya tarik gagasan kecerdasan majemuk telah memberi inspirasi terhadap pendidikan.

Tabel 1. Perbedaan setiap kecerdasan majemuk

\begin{tabular}{cc}
\hline Jenis Kecerdasan & Keterangan \\
\hline Interpersonal & Sanggup bekerja sama dengan orang lain \\
\hline Intrapersonal & Memahami kekuatan dan kelemahan diri \\
\hline Logis (Matematis) & Bisa melakukan penalaran runtut \\
\hline Verbal (Linguistik) & Cakap menggunakan perkataan \\
\hline Visual (Spasial) & Dapat untuk memvisualisasi dengan pikiran \\
\hline Musikal & Peka terhadap suara \\
\hline
\end{tabular}


Teori ilmiah yang baik dapat secara akurat menggambarkan perilaku dan memiliki kekuatan prediksi (Giancoli, 2014; Reece, dkk., 2011). Beberapa pertanyaan seperti, “Apakah gagasan kecerdasan majemuk memenuhi kriteria teori ilmiah?", "Apakah gagasan kecerdasan majemuk dapat diekspresikan secara kualitatif (seperti hubungan kesebandingan) dan/atau kuantitatif (misalnya dalam bentuk persamaan)?", "Mengapa kita harus menerima/menolak gagasan kecerdasan majemuk?", serta "Bagaimana gagasan kecerdasan majemuk dapat memprediksi hasil belajar?" adalah beberapa pertanyaan yang belum mendapat jawaban yang disepakati banyak pihak. Kami menganggap bahwa luaran kajian neurosains perlu dilibatkan sebagai bahan untuk menjawab pertanyaan tersebut.

Neurosains adalah kajian ilmiah tentang sistem syaraf. Sebagai disiplin ilmu, neurosains termasuk cabang multidisiplin karena menggabungkan psikologi, fisiologi, anatomi, biologi molekuler, biologi perkembangan, sitologi, serta pemodelan matematika untuk memahami sifat dasar dan sifat yang muncul dari neuron dan sirkuit saraf. Pembahasan neurosains berfokus kepada cara manusia sebagai individu menggali informasi dari lingkungan sekitar. Di sisi lain, pendidikan formal modern berfokus pada penjelasan tentang ruang lingkup yang tidak diharapkan timbul dari pembelajaran. Dari sini tampak bahwa neurosains dan pendidikan adalah dua hal yang bisa saling berpadu, bukan beradu.

Paduan antara neurosains dan pendidikan berpotensi menimbulkan tantangan baru bagi neurosains untuk beradaptasi dengan kebutuhan praktis pendidikan. Luaran dari tantangan ini kelak dapat member pijakan berupa karakteristik baru tentang keadaan pelajar-termasuk sekaligus bukan hanya keadaan otak, genetika, dan hormonal-yang berguna dalam pembelajaran. Di antara pijakan yang dapat dihasilkan tersebut adalah kecerdasan majemuk.

Kecerdasan majemuk yang diterima begitu saja oleh sebagian pihak, juga mendapat penolakan keras dari pihak lain. Penolak gagasan kecerdasan majemuk biasanya menolak dengan alasan minim bukti empiris (Waterhouse, 2006). Mereka menganggap bahwa kecerdasan umum memiliki keabsahan karena terdapat banyak data uji yang dikumpulkan sekitar 100 tahun, sementara tidak terdapat tes untuk mengukur delapan kecerdasan majemuk. Namun alasan ini justru membuka kedok bahwa banyak terbitan neurosains terkait kecerdasan majemuk yang belum dibaca atau bahkan tidak dapat dimengerti oleh para penolak gagasan kecerdasan majemuk.

Sampai 11 Oktober 2019 ini, telah terdapat sekitar 300-400 kajian empiris terhadap fungsi otak untuk melihat kesesuaian antara keterampilan dan kemampuan dari setiap kecerdasan majemuk (Shearer, 2019; Shearer \& Karanian, 2017). Sebagian besar kajian tersebut dilakukan melalui eksperimen fMRI (functional magnetic resonance imaging, penggambaran resonansi magnetik fungsional). Eksperimen fMRI biasa dipakai untuk mengukur aktivitas otak dengan mendeteksi perubahan aliran darah ke otak. Keperluan menggunakan eksperimen fMRI dalam kajian tersebut ialah agar keandalan data dapat maksimal. Sayang hal ini mungkin luput dari pengamatan sebagian peneliti pendidikan, baik yang berposisi langsung menerima atau segera menolak gagasan kecerdasan majemuk.

Beberapa kajian tersebut antara lain diulas oleh Shearer \& Karanian (2017), yang mencakup 318 artikel akademik terkait kajian empiris neurosains terhadap kecerdasan majemuk. 
Hasilnya menunjukkan bahwa kecerdasan majemuk memiliki pola saraf yang jelas dan koheren yang sebanding terhadap pola yang diidentifikasi dengan kecerdasan umum.

Shearer (2019) melanjutkan ulasan tersebut ketika menelaah 417 kajian neurosains terkait korelasi antara saraf dengan unit keterampilan dalam tujuh kecerdasan. Simpulan yang diperoleh menemukan setiap kecerdasan adalah unit keterampilan kognitif yang memiliki keunikan dan kesamaan dalam saraf (Shearer, 2019). Shearer (2019) menambahkan bahwa gagasan kecerdasan majemuk sulit untuk diselidiki secara langsung karena sifat abstrak dari kecerdasan yang ditunjuk sebagai gabungan keterampilan dan kinerja kognitif.

Kedua uraian tersebut memberi dasar untuk menguji secara eksperimental gagasan tentang kecerdasan (majemuk dan umum). Namun, karena aspek sosial dari kecerdasan, deskripsi saraf untuk kecerdasan majemuk mungkin hanya dapat menghasilkan semacam kerangka kerja sederhana ketimbang pembahasan utuh dan menyeluruh.

Memang eksperimen fMRI tekait fungsi otak memiliki beberapa batasan, antara lain tidak memberi garansi penelitian yang telah dilakukan mudah direplikasi, memfokuskan bagian otak tertentu sekaligus mengabaikan bagian lain ketika eskperimen, serta masih membutuhkan banyak kajian dan ulasan tentang interaksi dinamis antara berbagai struktur saraf. Walau begitu, eksperimen fMRI berhasil memberi rincian untuk menunjukkan bahwa gagasan kecerdasan majemuk selaras dengan perkembangan pengertian cara pikiran dan otak berinteraksi. Luaran yang dihasilkan memberi dukungan kepada pendapat bahwa setiap jenis dari 8 ragam kecerdasan majemuk memiliki bentuk saraf yang unik.

Tabel 2. Kaitan antara kecerdasan majemuk dengan wilayah otak

\begin{tabular}{|c|c|c|}
\hline Jenis Kecerdasan & Bagian Otak & Letak \\
\hline Interpersonal & $\begin{array}{l}\text { Frontal } \\
\text { Temporal } \\
\text { Cingulate } \\
\text { Parietal }\end{array}$ & $\begin{array}{c}\text { Medial-Temporal } \\
\text { Amygdala } \\
\text { Dorsolateral Prefrontal Cortex (PFC) } \\
\text { Anterior Cingulate Cortex (ACC) } \\
\text { Superior Temporal Sulcus (STS) }\end{array}$ \\
\hline Intrapersonal & $\begin{array}{l}\text { Frontal } \\
\text { Cingulate } \\
\text { Temporal } \\
\text { Parietal } \\
\text { Subcortical }\end{array}$ & $\begin{array}{c}\text { Prefrontal-Cortex } \\
\text { Anterior Cingulate cortex (ACC) } \\
\text { Dorsolateral Prefrontal Cortex (PFC) } \\
\text { Lateral Prefrontal } \\
\text { Ventromedial Prefrontal Cortex (vmPFC) }\end{array}$ \\
\hline Logis (Matematis) & $\begin{array}{c}\text { Frontal } \\
\text { Parietal } \\
\text { Temporal }\end{array}$ & $\begin{array}{c}\text { Prefrontal Cortex } \\
\text { Intraparietal Sulcus (IPS) } \\
\text { Inferior Parietal Lobule }\end{array}$ \\
\hline Verbal (Linguistik) & $\begin{array}{l}\text { Temporal } \\
\text { Frontal } \\
\text { Parietal }\end{array}$ & $\begin{array}{c}\text { Superior Temporal Gyrus (STG) } \\
\text { Inferior Frontal Gyrus } \\
\text { Area Broca } \\
\text { Posterior Inferior Frontal Gyrus }\end{array}$ \\
\hline Visual (Spasial) & $\begin{array}{l}\text { Frontal } \\
\text { Parietal } \\
\text { Temporal } \\
\text { Occipital }\end{array}$ & $\begin{array}{c}\text { Superior Temporal Gyrus (STG) } \\
\text { Premotor Cortex } \\
\text { Motor Cortex } \\
\text { Medial Temporal } \\
\text { Prefrontal } \\
\end{array}$ \\
\hline Musikal & Frontal & Superior Temporal Gyrus (STG) \\
\hline
\end{tabular}




\begin{tabular}{ccc}
\hline & Temporal & Primary Auditory Cortex \\
& Subcortical & Premotor Cortex \\
Cerebellum & Basal Ganglia \\
& Frontal & Supplementary Motor Area (SMA) \\
\hline \multirow{2}{*}{ Kinestetik (Jasmani) } & Parietal & Primary Motor Cortex \\
& Subcortical & Premotor Cortex \\
& Cerebellum & Basal Ganglia \\
\hline & & Superior Temporal Sulcus (STS) \\
Naturalis & Temporal & Brainstem (Batang Otak) \\
& Subcortical & Thalamus \\
& & Midbrain (Mesencephalon / Otak Tengah) \\
& Basal Ganglia \\
\hline
\end{tabular}

Kecerdasan adalah potensi diri untuk memproses informasi yang dari lingkungan sekitar untuk digunakan dalam mengambil keputusan, menyelesaikan masalah, dan/atau atau menghasilkan produk yang bernilai. Kecerdasan berbeda dari keterampilan dalam kedalaman, jangkauan, dan kerumitannya. Masing-masing kecerdasan majemuk merupakan gabungan dari keterampilan terkait dan hal ini menjelaskan bentuk sarafnya yang rumit. Pendidikan secara umum bertujuan upaya menumbuhkan kesadaran bahwa seseorang memiliki kecerdasan yang dapat dikembangkan dan digunakan untuk memenuhi kebutuhan diri serta mengembangkan masyarakat. Perspektif kecerdasan majemuk berkontribusi pada upaya ini. Memahami tentang langkah pembelajaran yang dapat mengembangkan kecerdasan intrapersonal memberi sarana kepada pelajar untuk lebih menyadari kehadiran diri sebagai bagian lingkungan. Penerapan temuan neurosains dalam pembelajaran adalah upaya rumit yang untuk saat ini mungkin baru berada di awal perjalanan panjang menuju interaksi efektif antara pakar neurosains dan pelaku pendidikan.

\section{PENUTUP}

Uraian yang telah disampaikan menunjukkan bahwa gagasan kecerdasan majemuk selaras dengan perkembangan pengertian cara pikiran dan otak berinteraksi. Setiap kecerdasan adalah unit keterampilan kognitif yang memiliki keunikan dan kesamaan dalam saraf dengan perbedaan pola yang jelas dan koheren. Dapat dikatakan bahwa kajian empiris dalam neurosains menyediakan bahan dukungan terhadap gagasan kecerdasan majemuk.

Tentunya walau terdapat kecerdasan majemuk, pelajar tidak boleh diberi label dengan jenis kecerdasan tertentu. Pelabelan, seperti menyebut 'cerdas secara verbal' atau 'cerdas secara visual' memiliki bahaya laten ketika membuat pelajar enggan mengeksplorasi variasi cara belajar maupun mengembangkan jenis kecerdasan lain 'yang lebih lemah'. Dengan demikian, pengertian terhadap kecerdasan majemuk pelajar sebaiknya diperlakukan sebagai bahan masukan kepada pendidik ketika merencanakan maupun mengubah secara mendadak pelaksanaan pembelajaran.

Ketika para pendidik di seluruh dunia sedang mengeksplorasi beragam cara untuk menerapkan gagasan kecerdasan majemuk dalam pembelajaran, pakar neurosains sedang berusaha memberi jawaban tentang cara agar proses dalam otak dapat meningkatkan hasil belajar. Tentu hal ini belum terjawab seutuhnya. Namun, bukankah justru hal ini memberi arah baru bagi penelitian pendidikan? Penelitian hanya bermanfaat ketika hasilnya tidak pasti, 
begitu kita tahu jawabannya, betapapun menariknya topik yang diteliti, itu bukan penelitian lagi. Kami berharap agar para pelaku pendidikan dan pakar neurosains bekerja sama dalam menghasilkan kerangka kerja yang utuh untuk berbagai faktor yang mempengaruhi pembelajaran. 


\section{REFERENSI}

al-Zarnūjīi, Burhān al-Dīn. (2015). Ta'līm al-muta 'allim țorīq al-ta 'allumi. Al-Maktab alIslāmī.

Candler, Laura. (2011). Teaching multiple intelligence theory. Teaching Resources URL: https://www.lauracandler.com/wp-content/uploads/2018/06/TPreview.pdf

Clement, Neville D., \& Lovat, Terence. (2012). Neuroscience and education: issues and challenges for curriculum. Curriculum Inquiry, 42(4), 534-557. DOI: https://doi.org/10.1111/j.1467-873X.2012.00602.x

Fuchs, Eberhard; \& Flügge, Gabriele. (2014, 04 Mei). Adult neuroplasticity: more than 40 years of research. Neural Plasticity: 541870. DOI: https://dx.doi.org/10.1155\%2F2014\%2F541870

Gardner, Howard Earl, \& Moran, Seana. (2006) The science of multiple intelligences theory: a response to lynn waterhouse. Educational Psychologist, 41(4): 227-232. DOI: https://doi.org/10.1207/s15326985ep4104_2

Gardner, Howard Earl. (2011). Multiple intelligences : the first thirty years. Harvard Graduate School of Education. URL:

https://howardgardner01.files.wordpress.com/2012/06/intro-frames-ofmind_30-years.pdf

Giancoli, Douglas C. (2014). Phys ics principles with applications (7th edition). Pearson Education.

Jung, Rex E., \& Haier, Richard J. (2007, 26 Juli). The Parieto-Frontal Integration Theory (PFIT) of intelligence: converging neuroimaging evidence. Behavioral and Brain Sciences, 30(2): 135-154. DOI: https://doi.org/10.1017/S0140525X07001185

Kweldju, Siusana. (2015, Juli - Desember). Neurobiology research findings: how the brain works during reading. PASAA: Journal of Language Teaching and Learning in Thailand, 50:125-142. URL: https://eric.ed.gov/?id=EJ1088308

Oliver, Mary. (2011, 07 September). Towards an understanding of neuroscience for science educators. Studies in Science Education, 47(2): 211-235. DOI: https://doi.org/10.1080/03057267.2011.604478

Reece, Jane B., dkk. (2011). Campbell biology (9th edition). Pearson Education.

Shearer, C. Branton, \& Karanian, Jessica M. (2017, March). The neuroscience of intelligence: Empirical support for the theory of multiple intelligences?. Trends in neuroscience and education, 6: 211-223. DOI: https://doi.org/10.1016/j.tine.2017.02.002

Shearer, C. Branton. (2019, 19 Juni). A detailed neuroscientific framework for the multiple intelligences: describing the neural components for specific skill units within each intelligence. Journal of Psychological Studies, 11 (3): 1-26. URL: http://www.ccsenet.org/journal/index.php/ijps/article/view/0/39826

Siayah, Syarofis; Kurniawati, Novi Khoirunnisa; \& Setiawan, Adib Rifqi. (2020, 29 Februari). Six Main Principles for Quality Learning based on "Ta'lìm alMuta'allim Țorīq al-Ta'allum". Thesis Commons. DOI: https://doi.org/10.31237/osf.io/gtq4m

University of Minnesota. (2010). Defining and measuring intelligence. Dalam Introduction to Psychology. University of Minnesota Libraries Publishing. DOI: https://dx.doi.org/10.24926/8668.1201

Waterhouse, Lynn. (2006). Inadequate evidence for multiple intelligences, mozart effect, and emotional intelligence theories. Educational Psychologist, 41:4, 247-255, DOI: https://doi.org/10.1207/s15326985ep4104_5 